\title{
Multiple analytical methods for determination of formoterol and glycopyrronium simultaneously in their novel combined metered dose inhaler
}

\author{
Yomna A. Salem ${ }^{1,2^{*}}$ (D) Mohammed E. A. Hammouda ${ }^{1,2}$, Mohamed A. Abu El-Enin ${ }^{1}$ and Saadia M. El-Ashry ${ }^{1}$
}

\begin{abstract}
One of the major causes of mortality all over the world is chronic obstructive pulmonary disease (COPD). Recently approved combined inhaler of formoterol fumarate (FF) and glycopyrronium bromide (GLY) has been used in very low concentrations ( $\mu \mathrm{g}$ level/actuation) doses in COPD patients. The first spectrophotometric and advanced highly sensitive liquid chromatography has been achieved successfully throughout this study, permitting validated analysis of dual combined inhaler in raw material as well as pharmaceutical inhaled dosage form. Three sensitive analytical methods were carried out for the simultaneous assay of FF and GLY in their novel combined Metered dose inhaler (MDI). The first method depends on measuring the first derivative amplitudes at $208.27 \mathrm{~nm}$ for FF and at $213.27 \mathrm{~nm}$ and $239.86 \mathrm{~nm}$ for GLY, respectively. The second method depends on measurement of the first derivative of the ratio spectra at 214 or $229 \mathrm{~nm}$ for FF and 240 or $259 \mathrm{~nm}$ for GLY, respectively. For the spectrophotometric methods, the linearity ranges were $0.48-9.6 \mu \mathrm{g} / \mathrm{mL}$ for FF and $0.9-18 \mu \mathrm{g} / \mathrm{mL}$ for GLY. For the third method, valid ion-pairing chromatographic method was carried out applying $C_{18}$ column and isocratic mobile phase of $60 \% \mathrm{v} / \mathrm{v}$ acetonitrile and $40 \%$ $\mathrm{V} / \mathrm{V}$ deionized waster ( $\mathrm{pH} 3.0$ ) enclosing $0.025 \%$ sodium dodecyl sulfate, using UV detection adjusted to $210 \mathrm{~nm}$ and flow rate of $1.2 \mathrm{~mL} / \mathrm{min}$. For the ion-pairing chromatographic method, the linearity ranges were $0.048-4.8 \mu \mathrm{g} / \mathrm{mL}$ for FF and 0.09-9.0 $\mu \mathrm{g} / \mathrm{mL}$ for GLY. The developed methods are reproducible, valid and offer efficient resolution between formoterol and glycopyrronium using spectrophotometric methods and highly sensitive and precise chromatographic method. The percent recoveries of the inhaled drugs in their MDI were good. The method was successfully established for the quantitative analysis of FF and GLY in their combined pharmaceutical inhaler capsules to validate the therapeutic efficiency of the combined drugs in quality control labs.
\end{abstract}

Keywords: Formoterol fumarate (FF), Glycopyrronium bromide (GLY), Ratio derivative spectrophotometry, lon pair chromatography

\footnotetext{
*Correspondence: yomnasalem26@gmail.com

${ }^{1}$ Medicinal Chemistry Department, Faculty of Pharmacy, Mansoura

University, Mansoura 35516, Egypt

Full list of author information is available at the end of the article
} 


\section{Introduction}

Chronic obstructive pulmonary disease (COPD) represents a serious health problem affecting millions of people and it is the third causing of death in the world after ischemic heart diseases and stroke. The recommended guidelines for COPD therapy including long acting bronchodilator or muscarinic antagonist [1].

Formoterol fumarate(FF), $N$-[2-hydroxy-5-[(1R)-1-hydroxy-2-[[(2R)-1-(4-methoxyphenyl)propan-2-yl]amino] ethyl]phenyl]formamide, is an effective long-acting $\beta_{2}$ adrenoceptor agonist [2] (Fig. 1). It is used for relaxation of smooth muscles in asthma and chronic obstructive pulmonary disease (COPD) [3]. Glycopyrronium bromide (GLY), 3-[(cyclopentylhydroxyphenylacetyl)oxy]1,1-dimethyl-pyrrolidinium bromide [2], is a recently marketed long-acting muscarinic antagonist for maintenance treatment in COPD patients [4] (Fig. 1). Recently, the dual-bronchodilator mixture of FF and GLY is the recommended therapeutic choice for COPD patients due to its potent clinical efficacy and limited intake inhalation regimen [5].

Reviewing the literature survey, several methods were carried out for estimation of formoterol fumarate including spectrophotometry [6, 7], ultra performance liquid chromatography (UPLC) [8], gas chromatography mass spectrometric method (GC-MS) [9, 10], liquid chromatography [11-18], capillary electrophoresis [19-21]. Regarding, glycopyrronium bromide, few methods were described, including: UV [22, 23], conductometry [24], classical GC [25], HPLC [26-29], and advanced HPLCMS methods [30, 31].

Formoterol fumarate and glycopyrronium bromide are co-formulated in MDI to relieve severe COPD patients [5]. It is challenging to resolve FF and GLY in the same chromatographic elution time as they have different lipophilic character that is difficult to separate in the same
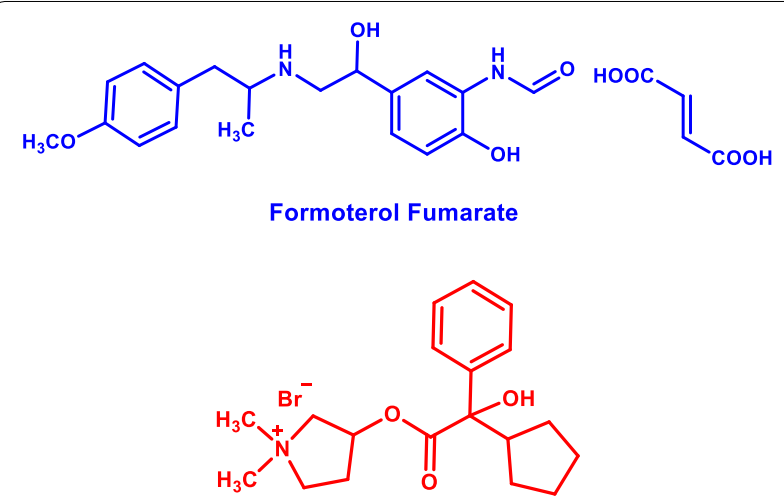

Glycopyrronium Bromide

Fig. 1 Structural formula of formoterol fumarate and glycopyrronium bromide run. GLY is less lipophilic than FF as given by their $\log \mathrm{p}$ values ( $\log \mathrm{p}$ values are -1.2 and 1.91 , respectively) [32].

Up till now, no spectrophotometric method has been described for the simultaneous assay of formoterol fumarate and glycopyrronium bromide in their combined MDI. Thus, it was necessary to perform the first precise, valid and reproducible spectrophotometric methods and isocratic, highly sensitive ion pair chromatographic (IPC) method to resolve GLY in the presence of FF in their raw materials and medicinally pressurized MDI in routine quality control analysis laboratories as well as therapeutic drug monitoring labs (Additional file 1).

\section{Experimental}

\section{Apparatus}

Spectrophotometric analysis was carried out on a Shimadzu (Kyoto, Japan) UV-1601 PC, UV-visible doublebeam spectrophotometer with matched $1-\mathrm{cm}$ path length quartz cells. The first derivative and the ratio derivative spectra of both drugs were derived in the wavelength range of $190-400 \mathrm{~nm}$ using $\Delta \lambda=8 \mathrm{~nm}$ for the first derivative of spectra and scaling factor $=10$.

The chromatographic assay was carried out using TM Series 200 Chromatograph Perkin Elmer instrument supplied with a $30 \mu \mathrm{L}$ loop of Rheodyne injector valve and a UV detection adjusted to $210 \mathrm{~nm}$.

$\mathrm{pH}-$ Meter (Consort NV P-901) was utilized for $\mathrm{pH}$ measurements throughout the work. Millipore filter (Sibata) was used for efficient filtration of mobile phase followed by degassing via Merck degasser (solvent L-7612). Mathematical data processing was performed using Total Chrom Workstation made in Massachusetts, USA.

\section{Materials and reagents}

- All the chemicals, solvents were of HPLC grade and efficiently purified deionized water was used throughout the work.

- Formoterol fumarate and internal standard namely dexamethasone (DEX) were obtained from SigmaAldrich chemicals (Steinheim, Germany). Glycopyrronium bromide authentic powder was gifted by Novartis (Switzerland). They were analyzed as given without applying further purification steps.

- Bevespi aerosphere ${ }^{\circledR}$; market labeled to eject $4.8 \mu \mathrm{g}$ $\mathrm{FF}$ and 9.0 $\mathrm{g}$ G GLY/inhalation (delivered dose), Foradil Breezhaler ${ }^{\circledR}$ contain $4.8 \mu \mathrm{g}$ of FF/inhaler capsule and Seebri Breezhaler ${ }^{\circledR}$ contain $50 \mu$ g of GLY/ inhaler capsule were obtained from commercial sources. 
- Sodium dodecyl sulphate (SDS), orthophosphoric acid (OPA), methanol and acetonitrile consumed throughout the work were HPLC grade and obtained from Sigma-Aldrich Chemie GmbH chemicals.

\section{Chromatographic conditions}

Knauer $\mathrm{C}_{18}$ column $(150 \mathrm{~mm} \times 4.6 \mathrm{~mm}$ with $5.0 \mu \mathrm{m}$ particle size) was applied for efficient resolution of FF and GLY at room temperature.

The components of mobile phase are carefully made to acetonitrile $(60 \% \mathrm{v} / \mathrm{v})$ : deionized water $(40 \% \mathrm{v} / \mathrm{v})$ and the ion pair SDS percentage of $0.025 \%$ added to the mobile phase and the final $\mathrm{pH}$ of 3.0 was adjusted using $0.02 \mathrm{M}$ OPA solution. An ultrasonic bath was utilized for mixing the mobile phase run components homogeneously for $30 \mathrm{~min}$, followed by membrane filtration through $0.45 \mu \mathrm{m}$ filter unit (Ireland), the gases were carefully ejected using an ultrasonic bath for $10 \mathrm{~min}$. The elution rate of mobile phase was adjusted to $1.2 \mathrm{~mL} / \mathrm{min}$ coupled with reproducible detector readings upon using UV wavelength of $210 \mathrm{~nm}$. The mobile phase was stable within 1 week when kept in refrigerator.

\section{Standard solution}

Ten $\mathrm{mg}$ of formoterol fumarate and $20.0 \mathrm{mg}$ of glycopyrronium bromide were added to $100 \mathrm{~mL}$ measuring flask containing methanol, to get $100 \mu \mathrm{g} / \mathrm{mL}$ FF stock solution and $200 \mu \mathrm{g} / \mathrm{mL}$ GLY stock solution for both methods. DEX (IS) stock solution $(300 \mu \mathrm{g} / \mathrm{mL})$ was obtained using methanol solvent that was used for further dilution of the stock solutions. Then, either methanol (in the spectrophotometric method) or mobile phase (in the IPC method) was added to achieve the working concentration ranges of combined drug solution. The stock FF and GLY solutions were $4{ }^{\circ} \mathrm{C}$ cooled, kept away from light.

\section{Construction of calibration graphs}

For the spectrophotometric methods, the concentration ranges of $0.48-9.6 \mu \mathrm{g} / \mathrm{mL}$ for formoterol fumarate and $0.9-18.0 \mu \mathrm{g} / \mathrm{mL}$ for glycopyrronium bromide were reached by accurate transfer of certain volumes of FF and GLY working solutions into volumetric flasks $(10 \mathrm{~mL})$. These flasks were further diluted with methanol to the mark and the zero-order absorption spectra were drawn against methanol.

Using first derivative spectrophotometric analysis, the values were determined at $208.27 \mathrm{~nm}$ for FF and 213.27, $239.86 \mathrm{~nm}$ for GLY, respectively. Plotting derivative amplitudes against each drug final concentration gave the calibration curve, in turns the equations of regression line could be concluded.
Regarding ratio derivative spectrophotometric analysis, the first derivative of the ratio spectra (the spectra of FF divided by the spectrum of $1.8 \mu \mathrm{g} / \mathrm{mL}$ GLY solution and the spectra of GLY divided by the spectrum of $3.6 \mu \mathrm{g} / \mathrm{mL}$ FF solution) were determined. The amplitudes were measured at 214 or $229 \mathrm{~nm}$ for FF and at 240 or $259 \mathrm{~nm}$ for GLY, respectively. The calibration curves were obtained upon plotting of derivative amplitudes versus each inhaled drug final concentration, as a result the regression line mathematical equations could be determined.

For the IPC method, transfer specified volumes of FF and GLY working solutions into volumetric flasks $(10 \mathrm{~mL})$ to achieve the linearity ranges of $0.048-4.8$ and $0.09-9.0 \mu \mathrm{g} / \mathrm{mL}$ of FF and GLY, respectively, then add constant $500 \mu \mathrm{L}$ DEX stock solution to reach final concentration of $15 \mu \mathrm{g} / \mathrm{mL}$. Before injection of $30 \mu \mathrm{L}$ combined drug mixture into HPLC, these flasks were further diluted by the mobile phase and the chromatographic separation temperature was adjusted to $25{ }^{\circ} \mathrm{C}$ (ambient temperature). The calibration curves were drawn upon plotting peak area ratio (FF and GLY peak area/DEX peak area) versus the drug concentration, as a result the regression line and mathematical equations could be constructed.

\section{Analysis of the formoterol fumarate/glycopyrronium bromide synthetic mixtures}

For all proposed methods, transfer aliquots of FF and GLY standard solutions preserving the therapeutic ratio of 1:1.875 into $10 \mathrm{~mL}$ volumetric flasks series. Then apply the same procedures described under "construction of calibration graphs" followed by calculating \% recoveries using the calibration graphs, or the corresponding regression equations.

\section{Analysis of FF and GLY in their combined metered-dose inhaler}

Ten doses of Bevespi aerosphere were delivered via vacuum into $10 \mathrm{~mL}$ of methanol for spectrophotometric methods and into $10 \mathrm{~mL}$ of mobile phase spiked with $300 \mu \mathrm{L}$ DEX stock solution for IPC methods to give working solutions containing $0.48 \mu \mathrm{g} / \mathrm{mL}$ of FF and $0.9 \mu \mathrm{g} / \mathrm{mL}$ of GLY. For the IPC method, before injection of combined drug mixture into the HPLC, $0.45 \mu \mathrm{m}$ sample filters was utilized for accurate filtration of all analyzed samples. Then apply the same procedures described under "Construction of calibration graphs" to analyze three different concentration of FF and GLY carefully selected from their working concentration. Finally, calculate the nominal content of each drug in their inhaled pharmaceuticals from the corresponding equations of regression. 


\section{Results and discussion}

\section{First derivative spectrophotometry (DS)}

It was observed that FF possesses UV absorption spectra with two $\lambda_{\max }$ at $217 \mathrm{~nm}$ and $252 \mathrm{~nm}$, while GLY possesses UV absorption spectra with two $\lambda_{\max }$ at $210 \mathrm{~nm}$ and $222 \mathrm{~nm}$ in methanol. Simultaneous determination of FF and GLY solution in methanol using conventional UV spectrophotometry showed interference of the zero order absorption spectra between the two drugs which could be resolved by derivative and ratio derivative spectrophotometry in order to analyze the mixture of the two drugs in their pharmaceuticals.

Figure 2 displays the first derivative spectra of both drugs by measuring FF first derivative amplitude at the zero crossing of GLY at $208.27 \mathrm{~nm}\left({ }^{1} \mathrm{D}_{208.27}\right)$, whereas GLY amplitude was measured at zero crossing point of FF at $213.27 \mathrm{~nm}$ and $239.86 \mathrm{~nm}$, respectively $\left({ }^{1} \mathrm{D}_{213.27,} 239.86\right)$ using $\Delta \lambda=8 \mathrm{~nm}$ and scaling factor $=10$.

\section{Ratio first derivative spectrophotometry (RDS)}

Figure 3 displays the first derivative of the ratio spectra of different concentrations of FF standards (FF spectra divided by the spectrum of a solution containing $1.8 \mu \mathrm{g} / \mathrm{mL}$ of GLY). In this figure, the amplitude at 214 or $229 \mathrm{~nm}\left({ }^{1} \mathrm{DD}_{214,229}\right)$ in the ratio derivative spectra corresponds to FF present in the solution.

Likewise, Fig. 4 explains the first derivative of the ratio spectra of different concentrations of GLY standards (GLY spectra divided by the spectrum of $3.6 \mu \mathrm{g} / \mathrm{mL}$ FF solution), on the basis of which, GLY could be quantified by measuring the amplitude at 240 or $259 \mathrm{~nm}\left({ }^{1} \mathrm{DD}_{240,259}\right)$.

The effect of $\Delta \lambda$ for the analysis of the first derivative of the ratio spectra was tried to get the ideal wavelength interval; $\Delta \lambda=8 \mathrm{~nm}$ was selected as appropriate for both drugs. For choosing the standard solution as mathematical divisor, separate concentrations were analyzed and

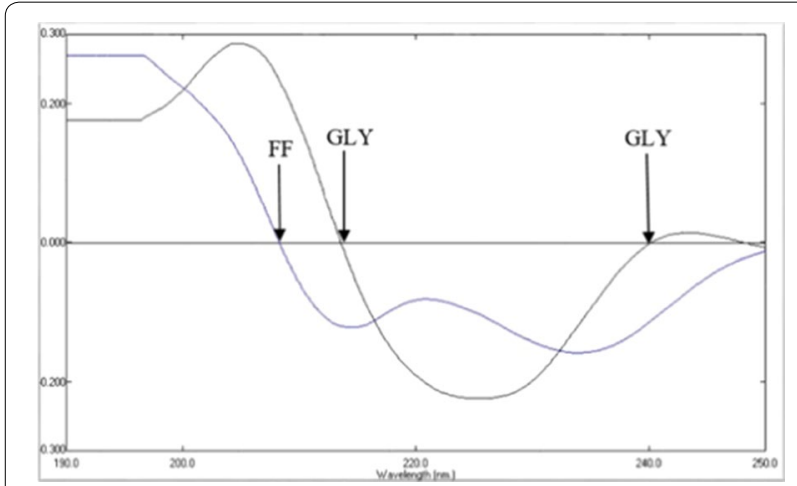

Fig. 2 First-order derivative spectra of $7.2 \mu \mathrm{g} / \mathrm{mL}$ FF and $13.5 \mu \mathrm{g} / \mathrm{mL}$ GLY in methanol, Where FF measured at $208.27 \mathrm{~nm}$ (at zero crossing for GLY) and GLY measured at $213.27 \mathrm{~nm}$ and $239.86 \mathrm{~nm}$ (at zero crossing for FF)

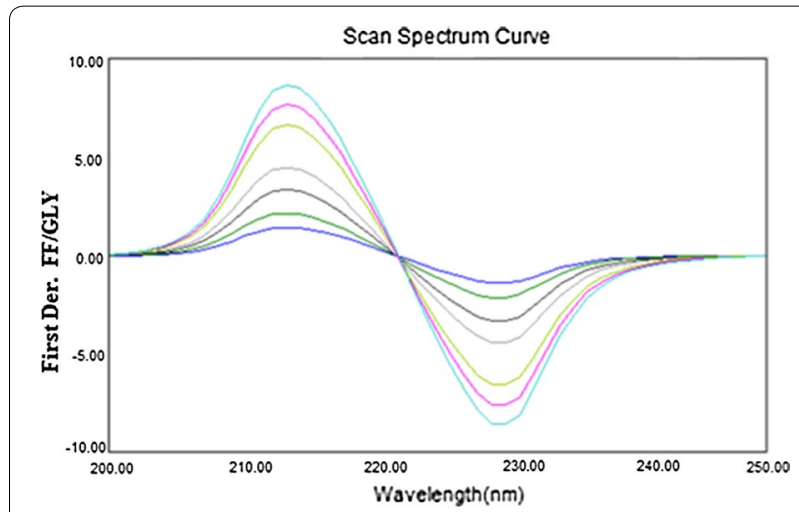

Fig. 3 First derivative of the ratio spectra of $F F(0.48,0.96,1.2,2.4,4.8$, 7.2 and $9.6 \mu \mathrm{g} / \mathrm{mL}$ ) when $1.8 \mu \mathrm{g} / \mathrm{mL}$ GLY was used as divisor (at 214, $229 \mathrm{~nm})$

their subsequent calibration curves were recorded. The ideal results depending on signal-to-noise ratio, sensitivity and repeatability parameters were acquired by using divisors of the spectra of $1.8 \mu \mathrm{g} / \mathrm{mL}$ FF and $3.6 \mu \mathrm{g} /$ $\mathrm{mL}$ GLY solutions in the calculation of GLY and FF, respectively.

\section{IPC method}

Ion pair chromatographic technique is broadly applied for efficient separation of both polar and non-ionic studied drug mixtures within the same run time [33]. This technique significantly enhances the symmetry of the resolved drug peaks, decreases the elution time coupled with high reproducibility of the results [34].

Different runs were tried without adding SDS as an ion pairing agent. Applying a mixture of $60 \% \mathrm{~V} / \mathrm{V}$ deionized water and $40 \% \mathrm{~V} / \mathrm{V}$ acetonitrile resulted in decreasing sensitivity with un-retained peak for FF. While using methanol instead of acetonitrile solvent eluted GLY within 14 min and exhibited a widely broad peak for GLY.

For the basic studied drugs; FF and GLY, it is critical to select negatively charged ion pairing agents (e.g. alkanesulfonates) to permit efficient separation of the combined drug mixture [33]. SDS is the best ion pairing agent selected due to its availability, economic price and its opposite charge to the basic studied analytes [35]. According to ion pair formation theory, the negatively charged part of SDS interacts with the positively charged analytes [34], while its lipophilic portion interacts with the column stationary phase [34]. As a result, ion pairing agent and the selected FF and GLY form non-charged paired complex that can be reserved and homogenously distributed between different phases consuming run time not exceeds 6 min (Fig. 5).

Critical Micellar concentration (CMC) of SDS at $25^{\circ} \mathrm{C}$ is $8.2 \mathrm{mM}$ [35], so the concentration used should be lower 


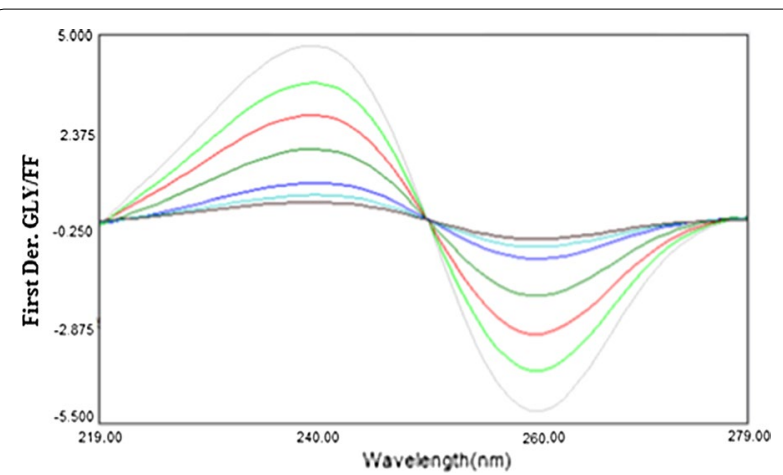

Fig. 4 First derivative of the ratio spectra of $\operatorname{GLY}(0.9,1.8,2.25,4.5$, 9, 13.5 and $18.0 \mu \mathrm{g} / \mathrm{mL}$ ) when $3.6 \mu \mathrm{g} / \mathrm{mL} F \mathrm{FF}$ was used as divisor (240, $259 \mathrm{~nm})$

than its CMC to avoid the micelle formation (formed in case of using concentration higher than its CMC). IPC is preferred due to its higher separation efficiency accompanied with repeatability of results [34].

Figures 5 and 6 exhibited the running chromatogram for FF and GLY solutions enclosing 2.4, $0.48 \mu \mathrm{g} / \mathrm{mL}$ and $4.5,0.9 \mu \mathrm{g} / \mathrm{mL}$ of each drug in their synthetic mixture and $4.5,0.9 \mu \mathrm{g} / \mathrm{mL}$ of each drug in synthetic mixture and MDI.

Excellent resolution coupled with high sensitivity was successfully achieved upon adding $0.025 \%$ SDS as an effective ion pair reagent to mobile phase. The established IPC elution time not exceeds $6 \mathrm{~min}$; The elution times of FF and GLY were 2.7 and $5.2 \mathrm{~min}$, respectively, as shown in Figs. 5 and 6. This method also enables the quantitative estimation of each drug.

\section{Method development and optimization}

The chromatographic elements that significantly affect the resolution of FF and GLY were examined and considered carefully. Calculation of chromatographic efficiency using; number of theoretical plates, resolution and capacity factor were best described in USP guidelines [36] and the results were shown in Table 1 . The $\mathrm{pH}$ of the mobile phases was altered over the range 3.0-6.0 using increasing volumes of OPA. The optimum $\mathrm{pH}$ of 3.0 was selected for separation and quantitation of both drugs as it provides satisfactory resolution $(\mathrm{Rs}=6.55)$ in short chromatographic run (5.2 min). Various Ratios of acetonitrile: deionized water was investigated. The optimum ratio was found to be $(60: 40, \mathrm{v} / \mathrm{v})$ acetonitrile: deionized water containing $0.025 \mathrm{SDS}$ at $\mathrm{pH}$ 3.0. This system provides the best sensitivity, resolution and the maximum peak efficiency as indicated by $\mathrm{N}$. As given in Table 1, different SDS concentrations within the range $(0.015-0.03 \%)$ were studied. Using SDS concentration of $0.015 \%$ resulted in decreasing the retention time of GLY and un-retained peak for FF. Meanwhile, it was found that increasing SDS

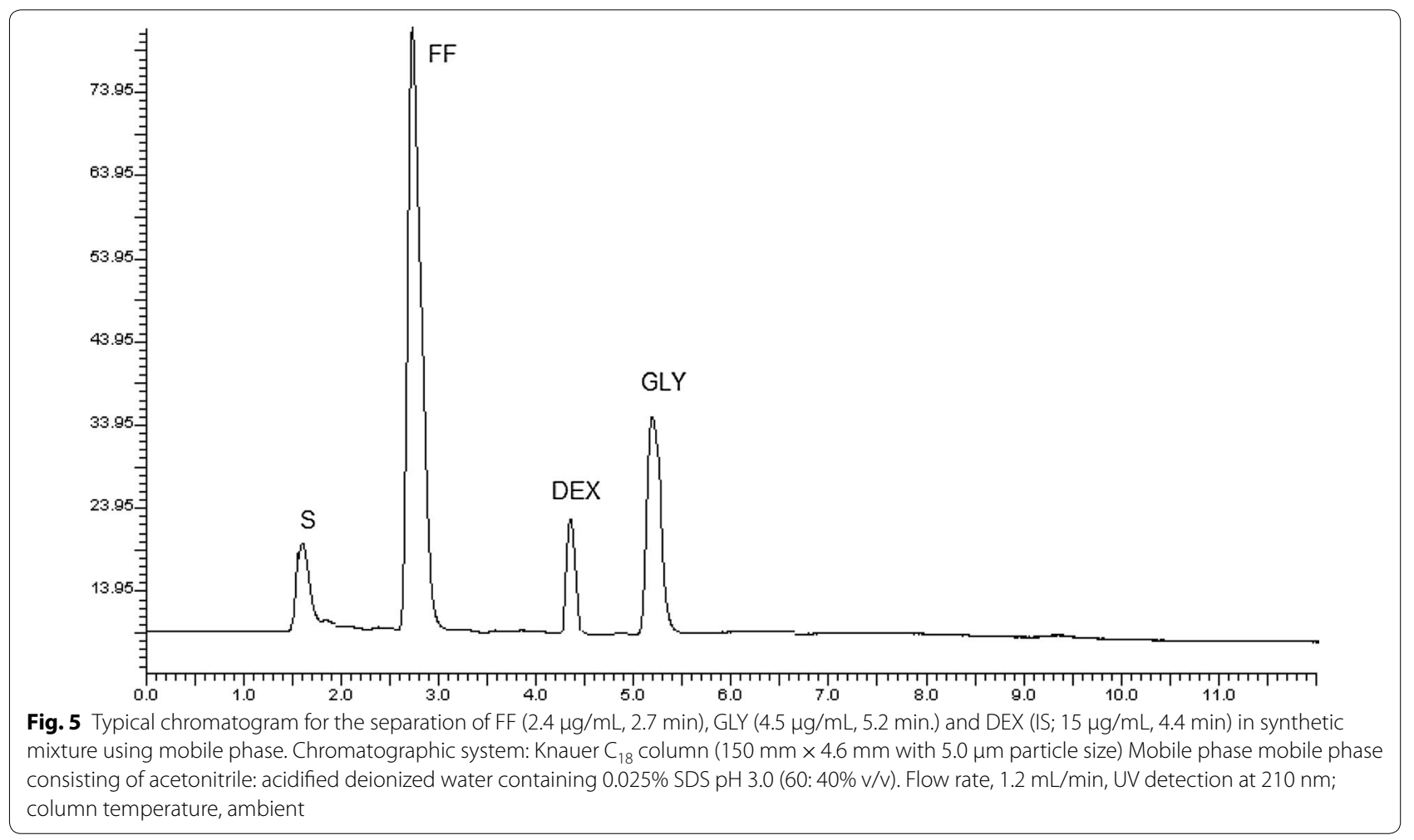




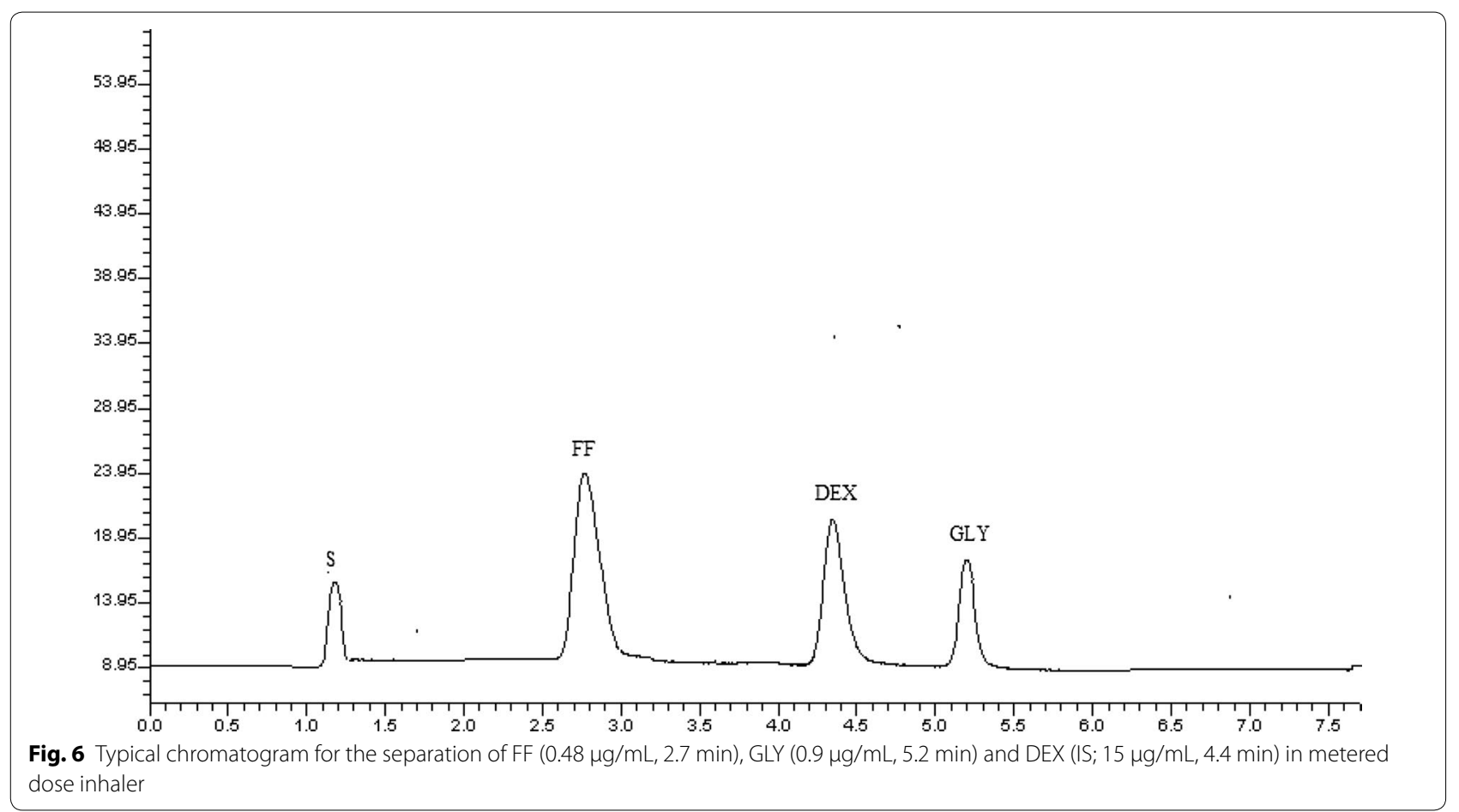

Table 1 Optimization of the chromatographic parameters for separation of mixture of FF and GLY by the proposed IPC method

\begin{tabular}{|c|c|c|c|c|c|c|c|}
\hline \multirow[t]{2}{*}{ Parameter } & & \multicolumn{2}{|c|}{ No. of theoretical plates $(\mathrm{N})$} & \multicolumn{2}{|c|}{$\begin{array}{l}\text { Mass distribution ratio } \\
(\mathrm{Dm})\end{array}$} & \multirow{2}{*}{$\begin{array}{l}\text { Resolution (Rs) } \\
\text { Rs }\end{array}$} & \multirow{2}{*}{$\begin{array}{l}\text { Relative } \\
\text { retention } \\
\text { (a) } \\
\text { PP }\end{array}$} \\
\hline & & $\mathrm{FF}$ & GLY & $\mathrm{FF}$ & GLY & & \\
\hline \multirow[t]{4}{*}{$\mathrm{pH}$} & 3.0 & 3274 & 2981 & 1.19 & 2.96 & 6.55 & 2.49 \\
\hline & 4.0 & 1213 & 2630 & 1.15 & 2.82 & 5.0 & 2.45 \\
\hline & 5.0 & 1024 & 2081 & 1.1 & 2.66 & 4.82 & 2.41 \\
\hline & 6.0 & 887 & 1673 & 1.08 & 2.65 & 4.39 & 2.45 \\
\hline \multirow[t]{2}{*}{ Organic modifier type } & Acetonitril & 3274 & 2981 & 1.19 & 2.96 & 6.55 & 2.49 \\
\hline & Methanol & 2036 & 1285 & 0.89 & 1.17 & 5.6 & 1.31 \\
\hline \multirow{5}{*}{$\begin{array}{l}\text { Ratio of [acidified water: ace- } \\
\text { tonitrile] } 0.025 \% \text { SDS }\end{array}$} & $(30: 70)$ & Un retai & & & & & \\
\hline & $(40: 60)$ & 3247 & 2981 & 1.19 & 2.96 & 6.55 & 2.49 \\
\hline & $(45: 55)$ & 2200 & 2410 & 1.27 & 3.05 & 4.92 & 2.39 \\
\hline & $(50: 50)$ & 2070 & 725 & 1.94 & 4.42 & 3.75 & 2.27 \\
\hline & $(60: 40)$ & 1834 & 512 & 2.14 & 4.78 & 4.5 & 2.23 \\
\hline \multirow[t]{4}{*}{ Conc. of SDS \% } & 0.015 & Un ret. & 1862 & 0 & 1.4 & 0 & 0 \\
\hline & 0.02 & 1246 & 2584 & 0.66 & 2.0 & 5.33 & 3.0 \\
\hline & 0.025 & 3274 & 2681 & 1.19 & 2.96 & 6.55 & 2.49 \\
\hline & 0.03 & 1601 & 1910 & 0.88 & 2.61 & 5.64 & 2.93 \\
\hline
\end{tabular}

Where: number of theoretical plates $(\mathrm{N})=5.45\left(\mathrm{t}_{\mathrm{R}} / \mathrm{W}_{\mathrm{h} / 2}\right)^{2}$

Resolution $(\mathrm{R})=2 \Delta \mathrm{t}_{\mathrm{R}} / \mathrm{W}_{1}+\mathrm{W}_{2}$

Mass distribution ratio $(D m)=t_{R}-t_{m} / t_{m}$

Relative retention $(\mathrm{a})=\mathrm{Dm}_{2} / \mathrm{Dm}_{1}$

$t_{R}$ is the retention time of the substance measured from the point of injection and $t_{M}$ is the retention time of a non-retained marker and $W_{h / 2}$ is the peak width at the half height

$W_{1}$ and $W_{2}$ are the width of the peaks of the two components at their bases 
concentration, increased the separation efficiency of both drugs as indicated by increased $\mathrm{N}$ up to $0.025 \%$; further increase in SDS concentration up to $0.03 \%$ resulted in a slight decrease in $\mathrm{N}$. The optimum SDS concentration was $0.025 \%$ as it provides the best sensitivity, reasonable run time and peak efficiency and selectivity (Table 1).

\section{Analytical performance}

Validation of the established methods were estimated as explained by ICH guidelines [37] (Table 2).

\section{Linearity}

The calibration curves were constructed by plotting either the derivative, ratio derivative amplitude or the peak area ratio [drug/IS] against each drug concentration in $\mu \mathrm{g} / \mathrm{mL}$ for the spectrophotometric or the IPC method, respectively. The graphs were found to be rectilinear over the concentration ranges mentioned in Table 2.

The subsequent equations were assumed by data analysis of the regression line (Table 2).

First derivative spectrophotometry:

\begin{tabular}{ll}
\hline$D A=-0.14+0.033 C(r=0.9999)$ & For FF at 208.27 nm $\left({ }^{1} D_{208.27}\right)$ \\
$D A=0.02+0.01 C(r=0.9999)$ & For GLY at 213.27 nm $\left({ }^{1} D_{213.27}\right)$ \\
$D A=0.002+0.013 C(r=0.9999)$ & For GLY at 239.86 nm ( $\left.{ }^{1} D_{239.86}\right)$ \\
\hline
\end{tabular}

Ratio first derivative method:

$\mathrm{DA}=0.99+0.87 \mathrm{C}(\mathrm{r}=0.9999)$

For FF at $233 \mathrm{~nm}\left({ }^{1} \mathrm{DD}_{214}\right)$

$\mathrm{DA}=-0.23+0.36 \mathrm{C}(\mathrm{r}=0.9999)$

For GLY at $260 \mathrm{~nm}\left({ }^{1} \mathrm{DD}_{240}\right)$
Where DA is derivative amplitude of the spectra at the cited wavelength, $C$ is the concentration of the drug $(\mu \mathrm{g} /$ $\mathrm{mL}$ ) and $\mathrm{r}$ is correlation coefficient.

IPC method:

\begin{tabular}{ll}
\hline$P A=-0.22+20.8 C(r=0.9999)$ & For FF \\
$P A=3.76+49.26 C(r=0.9999)$ & For GLY \\
\hline
\end{tabular}

PA is the Peak area ratio, $C$ is the drug concentration of $(\mu \mathrm{g} / \mathrm{mL})$ and $\mathrm{r}$ is correlation coefficient (Table 2).

Limit of quantification (LOQ) and limit of detection (LOD) The written equations were utilized to compute LOQ and LOD as suggested by ICH Q2 (R1) [37] (Table 2).

$$
\mathrm{LOQ}=10 \mathrm{Sa} / \mathrm{b} \text { and } \mathrm{LOD}=3.3 \mathrm{Sa} / \mathrm{b}
$$

where $\mathrm{Sa}=$ intercept of the standard deviation and $\mathrm{b}=$ the slope of calibration curve.

\section{Precision}

Triplicate trial assay of FF and GLY in their prepared mixture throughout the same day as recommended in intraday precision and for 3 separate successive days as recommended in inter day precision were established applying three altered concentrations of $0.6,1.2$ and $1.8 \mu \mathrm{g} / \mathrm{mL}$ for FF and 1.125, 2.25 and $3.375 \mu \mathrm{g} / \mathrm{mL}$ for GLY for the spectrophotometric methods and 4.8, 6.0 and $7.2 \mu \mathrm{g} / \mathrm{mL}$ for FF and at $6.75,9.0$ and $11.25 \mu \mathrm{g} / \mathrm{mL}$ for GLY for IPC method to confirm the validity of the studied method. The SD and RSD small values $(<2)$ exhibited the precision as well as \% Er small values $(<1)$ confirmed the method accuracy (Table 3 ).

Table 2 Analytical performance data for the determination of FF and GLY by the proposed methods

\begin{tabular}{|c|c|c|c|c|c|c|c|}
\hline \multirow[t]{2}{*}{ Parameter } & \multicolumn{3}{|l|}{ FF } & \multicolumn{4}{|l|}{ GLY } \\
\hline & $\mathrm{DS}_{208.27 n m}$ & $\mathrm{RDS}_{214 / 229 \mathrm{~nm}}$ & $I P C_{210 n m}$ & $D S 1_{213.27 n m}$ & DS2 $239.86 \mathrm{~nm}$ & $\operatorname{RDS}_{240 / 259 n m}$ & $I P C_{210 n m}$ \\
\hline Conc. range $(\mu \mathrm{g} / \mathrm{mL})$ & $0.48-9.6$ & $0.48-9.6$ & $0.048-4.8$ & $0.9-18$ & $0.9-18$ & $0.9-18$ & $0.09-0.9$ \\
\hline r & 0.9999 & 0.9999 & 0.9999 & 0.9999 & 0.9999 & 0.9999 & 0.9999 \\
\hline Slope & 0.033 & 0.87 & 20.8 & 0.01 & 0.013 & 0.36 & 49.26 \\
\hline Intercept & -0.014 & 0.99 & -0.22 & 0.02 & 0.002 & -0.23 & 3.76 \\
\hline LOD $(\mu \mathrm{g} / \mathrm{mL})$ & 0.06 & 0.04 & 0.018 & 0.15 & 0.08 & 0.17 & 0.051 \\
\hline $\mathrm{LOQ}(\mu \mathrm{g} / \mathrm{mL})$ & 0.19 & 0.1 & 0.055 & 0.46 & 0.28 & 0.52 & 0.154 \\
\hline $\mathrm{S}_{y / x}$ & $9.00 \times 10^{-4}$ & $1.4 \times 10^{-3}$ & 0.19 & $7.00 \times 10^{-4}$ & $4.00 \times 10^{-4}$ & $26.6 \times 10^{-3}$ & 1.31 \\
\hline $\mathrm{S}_{a}$ & $6.00 \times 10^{-4}$ & $1.00 \times 10^{-3}$ & 0.11 & $5.00 \times 10^{-4}$ & $3.00 \times 10^{-4}$ & $18.6 \times 10^{-3}$ & 0.76 \\
\hline$S_{b}$ & $1.00 \times 10^{-4}$ & $2.00 \times 10^{-4}$ & 0.04 & $4.80 \times 10^{-5}$ & $2.7 \times 10^{-5}$ & $1.8 \times 10^{-3}$ & 0.16 \\
\hline$\%$ RSD & 0.49 & 0.18 & 0.63 & 0.69 & 0.35 & 0.63 & 0.54 \\
\hline$\%$ Error & 0.15 & 0.06 & 0.2 & 0.22 & 0.11 & 0.2 & 0.17 \\
\hline
\end{tabular}

N.B.- $\mathrm{S} y / \mathrm{x}=$ standard deviation of the residuals

$\mathrm{Sa}=$ standard deviation of the intercept of regression line

$\mathrm{Sb}=$ standard deviation of the slope of regression line

$\%$ Error $=\mathrm{RSD} \% / \sqrt{ } \mathrm{n}$ 


\section{Accuracy}

Student's t-test and variance ratio $F$-test [38] were utilized to compare the results of assay of FF and GLY in MDI applying derivative spectrophotometry, ratio derivative spectrophotometry plus IPC methods and the comparison chromatographic method for the studied mixture. The outcomes in Tables 4, 5 and 6 showed no significant variance between the mentioned and

Table 3 Precision data of determination of the FF and GLY in pure form using (A) spectrophotometric method and (B) IPC method

\begin{tabular}{|c|c|c|c|c|c|c|}
\hline \multicolumn{7}{|l|}{ (A) Spectrophotometric method } \\
\hline \multirow{2}{*}{$\begin{array}{l}\text { Derivative spectrophotometric } \\
\text { method }\end{array}$} & \multicolumn{3}{|c|}{ FF Conc $208.27 \mathrm{~nm}(\mu \mathrm{g} / \mathrm{mL})$} & \multicolumn{3}{|c|}{$\mathrm{GLY}$ Conc $_{239.6 \mathrm{~nm}}(\mu \mathrm{g} / \mathrm{mL})$} \\
\hline & 4.8 & 6.0 & 7.2 & 6.75 & 9.0 & 11.25 \\
\hline \multicolumn{7}{|l|}{ Intra-day } \\
\hline $\bar{x}$ & 100.14 & 99.80 & 100.03 & 100.13 & 99.21 & 100.33 \\
\hline $\pm S D$ & 0.29 & 0.61 & 0.68 & 0.29 & 0.20 & 0.75 \\
\hline$\%$ RSD & 0.29 & 0.61 & 0.68 & 0.29 & 0.20 & 0.75 \\
\hline \% Error & 0.17 & 0.35 & 0.39 & 0.17 & 0.12 & 0.43 \\
\hline \multicolumn{7}{|l|}{ Inter-day } \\
\hline $\bar{x}$ & 100.12 & 100.24 & 99.86 & 100.14 & 99.60 & 100.12 \\
\hline $\pm S D$ & 0.21 & 0.52 & 0.95 & 0.75 & 0.42 & 0.55 \\
\hline$\%$ RSD & 0.21 & 0.52 & 0.95 & 0.74 & 0.42 & 0.55 \\
\hline \% Error & 0.12 & 0.30 & 0.55 & 0.43 & 0.24 & 0.32 \\
\hline \multirow{2}{*}{$\begin{array}{l}\text { Ratio derivative } \\
\text { spectrophotometric method }\end{array}$} & \multicolumn{3}{|c|}{ FF Conc $214 / 229 \mathrm{~nm}(\mu \mathrm{g} / \mathrm{mL})$} & \multicolumn{3}{|c|}{$\mathrm{GLY}_{\text {Conc }} 240 / 259 \mathrm{~nm}(\mu \mathrm{g} / \mathrm{mL})$} \\
\hline & 4.8 & 6.0 & 7.2 & 6.75 & 9.0 & 11.25 \\
\hline \multicolumn{7}{|l|}{ Intra-day } \\
\hline $\bar{x}$ & 99.89 & 100.07 & 99.82 & 100.64 & 100.74 & 99.91 \\
\hline$\pm \mathrm{SD}$ & 0.58 & 0.85 & 0.49 & 0.36 & 0.29 & 0.64 \\
\hline$\%$ RSD & 0.58 & 0.85 & 0.49 & 0.36 & 0.29 & 0.64 \\
\hline \% Error & 0.33 & 0.49 & 0.28 & 0.21 & 0.17 & 0.37 \\
\hline \multicolumn{7}{|l|}{ Inter-day } \\
\hline $\bar{x}$ & 100.53 & 100.08 & 100.43 & 99.82 & 99.44 & 100.47 \\
\hline $\pm S D$ & 0.23 & 0.54 & 0.75 & 0.96 & 0.13 & 0.76 \\
\hline$\%$ RSD & 0.23 & 0.54 & 0.74 & 0.96 & 0.13 & 0.75 \\
\hline$\%$ Error & 0.13 & 0.31 & 0.43 & 0.55 & 0.07 & 0.44 \\
\hline \multicolumn{7}{|l|}{ (B) IPC method } \\
\hline \multirow[t]{2}{*}{ IPC method } & \multicolumn{3}{|c|}{ FF Conc. $(\mu \mathrm{g} / \mathrm{mL})$} & \multicolumn{3}{|c|}{ GLY Conc. $(\mu \mathrm{g} / \mathrm{mL})$} \\
\hline & 0.6 & 1.2 & 1.8 & 1.125 & 2.25 & 3.375 \\
\hline \multicolumn{7}{|l|}{ Intra-day } \\
\hline $\bar{x}$ & 100.89 & 99.41 & 99.45 & 100.03 & 99.54 & 99.24 \\
\hline $\pm S D$ & 0.67 & 0.41 & 0.66 & 0.60 & 0.66 & 0.35 \\
\hline$\%$ RSD & 0.66 & 0.41 & 0.66 & 0.60 & 0.67 & 0.35 \\
\hline \% Error & 0.38 & 0.24 & 0.38 & 0.35 & 0.39 & 0.20 \\
\hline \multicolumn{7}{|l|}{ Inter-day } \\
\hline $\bar{x}$ & 99.84 & 99.60 & 99.48 & 99.95 & 100.58 & 99.66 \\
\hline $\pm S D$ & 0.44 & 0.37 & 0.60 & 0.53 & 0.62 & 0.45 \\
\hline$\%$ RSD & 0.44 & 0.37 & 0.61 & 0.53 & 0.61 & 0.45 \\
\hline$\%$ Error & 0.23 & 0.21 & 0.35 & 0.30 & 0.38 & 0.26 \\
\hline
\end{tabular}


comparison analytical methods regarding precision and accuracy. The comparison chromatographic method [39] relies on the assay of FF and GLY utilizing $\mathrm{C}_{18}$ column and the mobile phase composed of $0.1 \%$ OPA: methanol $(60: 40 \%, \mathrm{~V} / \mathrm{V})$, the $\mathrm{pH}$ adjusted to 3.0 , at $1.0 \mathrm{~mL} / \mathrm{min}$ flow rate and coupled with UV detection at $220 \mathrm{~nm}$.

\section{Robustness}

The consistence of the peak area measured values with the minor intended changes in the testing parameters was evaluated by the established IPC method. These parameters include; $\mathrm{pH}(3.0 \pm 0.1)$, acetonitrile: acidified water mobile phase proportional ratio $(60: 40 \pm 2 \% \mathrm{v} / \mathrm{v})$, and SDS added concentration $(0.025 \pm 0.0025 \% \mathrm{w} / \mathrm{v})$. These minor changes not negatively affect the peak area of both drugs.

\section{Selectivity and specificity}

Specificity of the proposed methods were assessed by the standard addition method on the dosage form. Known amounts of FF and GLY standards have been added at different concentrations (FF: 1.2, 2.4, $4.8 \mu \mathrm{g} /$ $\mathrm{mL}$; GLY: 2.25, 4.5, $9.0 \mu \mathrm{g} / \mathrm{mL}$ ). Triplicate assay was performed at each concentration level. Measurement of the percent recovery of the added analytes amount to the sample gave accuracy as given in Table 7 prove the accuracy of the proposed methods within the desired range.

\section{Analysis of formoterol fumarate/glycopyrronium bromide} in synthetic mixtures and co-formulated metered dose inhaler

Analysis of FF and GLY in pressurized MDI in their recommended therapeutic doses of $4.8 / 9$, respectively

Table 4 Assay results for the determination of the FF and GLY in their synthetic mixture and MDI by the proposed DS and reference methods

\begin{tabular}{|c|c|c|c|c|c|c|c|c|}
\hline & \multicolumn{4}{|c|}{ a. Proposed DS method (synthetic mixture) } & \multicolumn{4}{|c|}{ Reference method [39] } \\
\hline & \multicolumn{2}{|c|}{ Conc. taken $(\mu \mathrm{g} / \mathrm{mL})$} & \multicolumn{2}{|l|}{$\%$ Found $^{a}$} & \multicolumn{2}{|c|}{ Conc. taken $(\mu \mathrm{g} / \mathrm{mL})$} & \multicolumn{2}{|c|}{$\%$ Found $^{a}$} \\
\hline & FF & GLY & $\mathrm{FF}$ & GLY & $\mathrm{FF}$ & GLY & $\mathrm{FF}$ & GLY \\
\hline \multirow[t]{6}{*}{ Data } & 8.4 & 15.75 & 100.08 & 100.12 & 10.0 & 18.0 & 98.24 & 99.58 \\
\hline & 7.2 & 13.5 & 99.48 & 100.82 & 8.4 & 15.0 & 99.42 & 98.35 \\
\hline & 6 & 11.25 & 99.56 & 100.40 & 7.8 & 12.0 & 100.13 & 101.35 \\
\hline & 4.8 & 9 & 100.21 & 100.35 & 6.2 & 9.0 & 99.25 & 100.89 \\
\hline & 3.6 & 6.75 & 100.03 & 99.49 & 4.5 & 6.0 & 100.47 & 99.36 \\
\hline & 2.4 & 4.5 & 99.99 & 99.18 & 2.9 & 3.0 & 100.34 & 100.21 \\
\hline $\bar{x}$ & & & 99.89 & 100.06 & & & 99.92 & 99.96 \\
\hline $\pm S D$ & & & 0.29 & 0.61 & & & 0.55 & 1.1 \\
\hline t-value & & & $0.32(10.0)$ & $0.20(10.0)$ & & & & \\
\hline \multirow[t]{4}{*}{ F-value } & & & $3.62(5.5)$ & $3.16(5.5)$ & & & & \\
\hline & \multicolumn{4}{|c|}{ b. Proposed DS method (MDI) } & \multicolumn{4}{|c|}{ Reference method [39] } \\
\hline & \multicolumn{2}{|c|}{ Conc. taken $(\mu \mathrm{g} / \mathrm{mL})$} & \multicolumn{2}{|l|}{$\%$ Found $^{a}$} & \multicolumn{2}{|c|}{ Conc. taken $(\mu \mathrm{g} / \mathrm{mL})$} & \multicolumn{2}{|c|}{$\%$ Found $^{a}$} \\
\hline & $\mathrm{FF}$ & GLY & $\mathrm{FF}$ & GLY & $\mathrm{FF}$ & GLY & $\mathrm{FF}$ & GLY \\
\hline \multirow[t]{6}{*}{ Data } & 8.4 & 15.75 & 100.89 & 100.88 & 10.0 & 18.0 & 99.21 & 100.28 \\
\hline & 7.2 & 13.5 & 99.52 & 100.25 & 8.4 & 15.0 & 98.90 & 99.35 \\
\hline & 6 & 11.25 & 100.35 & 100.54 & 7.8 & 12.0 & 100.51 & 98.52 \\
\hline & 4.8 & 9 & 99.87 & 99.35 & 6.2 & 9.0 & 99.54 & 101.35 \\
\hline & 3.6 & 6.75 & 100.35 & 100.48 & 4.5 & 6.0 & 100.37 & 100.47 \\
\hline & 2.4 & 4.5 & 100.08 & 99.36 & 2.9 & 3.0 & 98.50 & 98.52 \\
\hline $\bar{x}$ & & & 100.18 & 100.14 & & & 99.51 & 99.75 \\
\hline $\pm S D$ & & & 0.47 & 0.67 & & & 0.33 & 1.14 \\
\hline t-value & & & $1.41(10.0)$ & $0.74(10.0)$ & & & & \\
\hline F-value & & & $3.24(5.5)$ & $3.17(5.5)$ & & & & \\
\hline
\end{tabular}

Nominal content for GLY in Bevespi ${ }^{\circledR}$ aerosphere by the proposed method $=9.0 \mu \mathrm{g} / \mathrm{buff}$

Each result is the average of three separate determinations

${ }^{\text {a }}$ Nominal content for FF in Bevespi ${ }^{\circledR}$ aerosphere by the proposed method $=4.8 \mu \mathrm{g} / \mathrm{buff}$ 
Table 5 Assay results for the determination of the FF and GLY in their synthetic mixture by the proposed RDS and reference methods

\begin{tabular}{|c|c|c|c|c|c|c|c|c|}
\hline & \multicolumn{4}{|c|}{ Proposed RDS method (synthetic mixture) } & \multicolumn{4}{|c|}{ Reference method [39] } \\
\hline & \multicolumn{2}{|c|}{ Conc. taken $(\mu \mathrm{g} / \mathrm{mL})$} & \multicolumn{2}{|l|}{$\%$ Found $^{a}$} & \multicolumn{2}{|c|}{ Conc. taken $(\mu \mathrm{g} / \mathrm{mL})$} & \multicolumn{2}{|c|}{$\%$ Found $^{a}$} \\
\hline & FF & GLY & $\mathrm{FF}$ & GLY & $\mathrm{FF}$ & GLY & $\mathrm{FF}$ & GLY \\
\hline \multirow[t]{6}{*}{ Data } & 7.8 & 15.25 & 99.24 & 99.41 & 11.0 & 19.0 & 99.42 & 101.25 \\
\hline & 6.6 & 13.0 & 100.351 & 99.97 & 9.4 & 16.0 & 98.24 & 100.58 \\
\hline & 5.4 & 10.75 & 99.54 & 100.89 & 8.8 & 13.0 & 99.31 & 100.36 \\
\hline & 4.2 & 8.5 & 99.42 & 100.87 & 7.2 & 10.0 & 100.45 & 99.34 \\
\hline & 3.0 & 6.25 & 100.94 & 100.39 & 5.5 & 7.0 & 99.78 & 99.24 \\
\hline & 1.8 & 4.0 & 99.67 & 99.77 & 3.9 & 4.0 & 98.54 & 98.36 \\
\hline $\bar{x}$ & & & 99.86 & 100.22 & & & 99.29 & 99.86 \\
\hline$\pm \mathrm{SD}$ & & & 0.65 & 0.60 & & & 0.81 & 1.6 \\
\hline t-value & & & $1.35(10.0)$ & $0.73(10.0)$ & & & & \\
\hline \multirow[t]{4}{*}{$F$-value } & & & $1.54(5.5)$ & $3.08(5.5)$ & & & & \\
\hline & \multicolumn{4}{|c|}{ Proposed RDS method (MDI) } & \multicolumn{4}{|c|}{ Reference method [39] } \\
\hline & \multicolumn{2}{|c|}{ Conc. taken $(\mu \mathrm{g} / \mathrm{mL})$} & \multicolumn{2}{|l|}{$\%$ Found $^{a}$} & \multicolumn{2}{|c|}{ Conc. taken $(\mu \mathrm{g} / \mathrm{mL})$} & \multicolumn{2}{|c|}{$\%$ Found $^{a}$} \\
\hline & $\mathrm{FF}$ & GLY & $\mathrm{FF}$ & GLY & $\mathrm{FF}$ & GLY & $\mathrm{FF}$ & GLY \\
\hline \multirow[t]{6}{*}{ Data } & 7.8 & 15.25 & 99.25 & 100.87 & 11.0 & 7.93 & 99.02 & 100.05 \\
\hline & 6.6 & 13.0 & 100.74 & 99.68 & 9.4 & 7.98 & 99.21 & 101.35 \\
\hline & 5.4 & 10.75 & 100.92 & 99.35 & 8.8 & 8.00 & 98.21 & 98.35 \\
\hline & 4.2 & 8.5 & 100.24 & 100.97 & 7.2 & & 99.74 & 99.65 \\
\hline & 3.0 & 6.25 & 99.52 & 100.22 & 5.5 & & 100.38 & 99.35 \\
\hline & 1.8 & 4.0 & 100.34 & 100.98 & 3.9 & & 99.17 & 98.35 \\
\hline $\bar{x}$ & & & 100.17 & 100.35 & & & 99.29 & 99.52 \\
\hline $\pm S D$ & & & 0.66 & 0.71 & & & 0.73 & 1.13 \\
\hline t-value & & & $2.19(10.0)$ & $1.52(10.0)$ & & & & \\
\hline F-value & & & $1.21(5.5)$ & $2.55(5.5)$ & & & & \\
\hline
\end{tabular}

Nominal content for GLY in Bevespi ${ }^{\circledR}$ aerosphere by the proposed method $=9.0 \mu \mathrm{g} / \mathrm{buff}$

Each result is the average of three separate determinations

a Nominal content for FF in Bevespi ${ }^{\circledR}$ aerosphere by the proposed method $=4.8 \mu \mathrm{g} / \mathrm{buff}$

was performed applying the proposed methods in their pressurized metered dose inhaler and synthetic mixtures. The results found in Tables 4,5 and 6 are reproducible and accurate as given by the good \% recoveries which enable precise analysis of FF and GLY in the quality control labs. The high specificity of the proposed method was revealed as the inhaler propellant, hydrofluoroalkane that was repelled throughout inhalation has negligible effect on the inhaled drugs measured in MDI.

\section{Conclusion}

Simple and valid spectrophotometric and liquid chromatographic methods were carried out successfully for the analysis of formoterol fumarate and glycopyrronium bromide in their raw materials as well as pharmaceutical metered dose inhaler. The developed spectrophotometric methods for the simultaneous analysis of FF and GLY are simple, available, and time saving. Highly sensitive and accurate ion-pairing liquid chromatographic method was successfully established for simultaneous estimation of both FF and GLY in pure form as well as in the MDI with short run time not exceeds $6 \mathrm{~min}$ and good resolution $\left(R_{s}>2\right)$. Compared with the studied spectrophotometric method, the IPC method is highly sensitive and specific. The \% RSD and LOD are satisfactorily good for quality control drug analysis without interference from the common excipients and the ejected propellant of MDI. 
Table 6 Assay results for the determination of the FF and GLY in their synthetic mixture by the proposed IPC and reference methods

\begin{tabular}{|c|c|c|c|c|c|c|c|c|}
\hline & \multicolumn{4}{|c|}{ Proposed IPC method (synthetic mixture) } & \multicolumn{4}{|c|}{ Reference method [39] } \\
\hline & \multicolumn{2}{|c|}{ Conc. taken $(\mu \mathrm{g} / \mathrm{mL})$} & \multicolumn{2}{|l|}{$\%$ Found $^{a}$} & \multicolumn{2}{|c|}{ Conc. taken $(\mu \mathrm{g} / \mathrm{mL})$} & \multicolumn{2}{|c|}{$\%$ Found $^{a}$} \\
\hline & FF & GLY & $\mathrm{FF}$ & GLY & $\mathrm{FF}$ & GLY & $\mathrm{FF}$ & GLY \\
\hline \multirow[t]{6}{*}{ Data } & 3.6 & 6.75 & 99.42 & 100.12 & 9.6 & 13.5 & 99.38 & 99.58 \\
\hline & 3.0 & 5.625 & 99.34 & 100.82 & 7.2 & 11.25 & 98.34 & 98.32 \\
\hline & 2.4 & 4.5 & 100.35 & 100.4 & 4.8 & 9.0 & 99.25 & 99.25 \\
\hline & 1.8 & 3.375 & 100.97 & 100.35 & 3.6 & 6.75 & 100.38 & 99.87 \\
\hline & 1.2 & 2.25 & 99.57 & 99.49 & 2.4 & 4.5 & 99.07 & 100.77 \\
\hline & 0.6 & 1.125 & 99.34 & 99.18 & 1.2 & 2.25 & 98.34 & 100.82 \\
\hline $\bar{x}$ & & & 99.83 & 100.06 & & & 99.13 & 99.77 \\
\hline $\pm S D$ & & & 0.68 & 0.61 & & & 0.76 & 0.95 \\
\hline t-value & & & $1.7(10.0)$ & $0.63(10.0)$ & & & & \\
\hline \multirow[t]{4}{*}{$F$-value } & & & $1.27(5.5)$ & $2.41(5.5)$ & & & & \\
\hline & \multicolumn{4}{|c|}{ Proposed IPC method (MDI) } & \multicolumn{4}{|c|}{ Reference method [39] } \\
\hline & \multicolumn{2}{|c|}{ Conc. taken $(\mu \mathrm{g} / \mathrm{mL})$} & \multicolumn{2}{|l|}{$\%$ Found $^{a}$} & \multicolumn{2}{|c|}{ Conc. taken $(\mu \mathrm{g} / \mathrm{mL})$} & \multicolumn{2}{|c|}{$\%$ Found $^{a}$} \\
\hline & FF & GLY & $\mathrm{FF}$ & GLY & $\mathrm{FF}$ & GLY & $\mathrm{FF}$ & GLY \\
\hline \multirow[t]{6}{*}{ Data } & 3.6 & 6.75 & 99.87 & 100.52 & 9.6 & 13.5 & 99.94 & 100.85 \\
\hline & 2.7 & 5.625 & 99.68 & 100.33 & 7.2 & 11.25 & 99.88 & 100.35 \\
\hline & 1.8 & 4.5 & 99.35 & 100.08 & 4.8 & 9.0 & 100.94 & 100.39 \\
\hline & 0.9 & 3.375 & 100.87 & 99.52 & 3.6 & 6.75 & 99.72 & 98.33 \\
\hline & 0.45 & 2.25 & 100.24 & 99.68 & 2.4 & 4.5 & 99.40 & 99.58 \\
\hline & 0.36 & 1.125 & 99.34 & 100.48 & 1.2 & 2.25 & 99.24 & 99.07 \\
\hline $\bar{x}$ & & & 99.89 & 100.1 & & & 99.85 & 99.76 \\
\hline$\pm \mathrm{SD}$ & & & 0.59 & 0.42 & & & 0.60 & 0.95 \\
\hline t-value & & & $0.11(10.0)$ & $0.8[10]$ & & & & \\
\hline F-value & & & $1.04(5.5)$ & $5.06(5.5)$ & & & & \\
\hline
\end{tabular}

Nominal content for GLY in Bevespi ${ }^{\circledast}$ aerosphere by the proposed method $=9.0 \mu \mathrm{g} / \mathrm{buff}$

Each result is the average of three separate determinations

${ }^{\text {a }}$ Nominal content for FF in Bevespi ${ }^{\circledR}$ aerosphere by the proposed method $=4.8 \mu \mathrm{g} / \mathrm{buff}$

Table 7 Accuracy of the proposed methods using standard addition method

\begin{tabular}{|c|c|c|c|c|c|c|c|}
\hline \multirow{2}{*}{\multicolumn{2}{|c|}{$\begin{array}{l}\text { Added concentration } \\
{\text { to } B e v e s p i^{\circledR} \text { aerosphere }}^{\circledR} \\
0.48,0.9(\mu \mathrm{g} / \mathrm{mL})\end{array}$}} & \multicolumn{6}{|c|}{$\%$ Recovery $^{a}$} \\
\hline & & \multicolumn{3}{|l|}{$\mathrm{FF}$} & \multicolumn{3}{|l|}{ GLY } \\
\hline $\mathrm{FF}$ & GLY & DS & RDS & IPC & DS & RDS & IPC \\
\hline 1.2 & 2.25 & 100.51 & 99.1 & 100.95 & 99.1 & 99.47 & 100.26 \\
\hline 2.4 & 4.5 & 99.83 & 99.83 & 100.32 & 99.79 & 100.55 & 99.75 \\
\hline 4.8 & 9.0 & 99.31 & 100.43 & 99.24 & 100.3 & 99.84 & 100.63 \\
\hline \multicolumn{2}{|c|}{ Mean \pm RSD \% } & $99.88 \pm 0.49$ & $99.81 \pm 0.55$ & $100.1 \pm 0.72$ & $99.76 \pm 0.50$ & $99.93 \pm 0.45$ & $100.13 \pm 0.4$ \\
\hline
\end{tabular}

Each result is the average of three separate determinations

a Nominal content for FF Bevespi ${ }^{\circledR}$ aerosphere by the proposed method $=9.0 \mu \mathrm{g} / \mathrm{buff}$, Nominal content for GLY in Bevespi ${ }^{\circledR}$ aerosphere by the proposed method $=4.8 \mu \mathrm{g} / \mathrm{buff}$, assay was performed on three levels, each result is the average of three separate determinations 


\section{Additional file}

Additional file 1. Illustrative data and figures that described in detail the optimization of the chromatographic performance and system suitability for HPLC method according to USP guidelines.

\section{Abbreviations}

FF: formoterol fumarate; GLY: glycopyrronium bromide; IPC: ion pair chromatography; OPA: orthophosphoric acid.

\section{Acknowledgements}

All authors would like to thank Faculty of Pharmacy, Mansoura University for his support and providing the possible facilities for completing this work.

\section{Authors' contributions}

YS performed all the experimental work, besides writing the manuscript. $\mathrm{MH}$ participated in design of the study, results discussion and sample preparation. MA contributed reagents and chemicals. SA as a project leader participated in the design of the study and revise the manuscript. All authors read and approved the final manuscript.

\section{Funding}

All authors confirm that there's no funding absolutely for this work.

\section{Availability of data and materials}

All relevant supporting data are fully available without any restriction.

\section{Competing interests}

The authors declare that they have no competing interests.

\section{Author details}

1 Medicinal Chemistry Department, Faculty of Pharmacy, Mansoura University, Mansoura 35516, Egypt. ${ }^{2}$ Pharmaceutical Chemistry Department, Faculty of Pharmacy, Horus University-Egypt (HUE), New Damietta, Egypt.

Received: 24 January 2019 Accepted: 31 May 2019

Published online: 10 June 2019

\section{References}

1. Council GM, Commission GBM (2014) British pharmacopoeia. General Medical Council, London

2. Wilson CO, Beale JM, Block JH (2011) Wilson and Gisvold's textbook of organic medicinal and pharmaceutical chemistry, 12th edn. Lippincott Williams \&Wilkins, Philadelphia

3. Fozard JR, Buescher H (2001) Comparison of the anti-bronchoconstrictor activities of inhaled formoterol, its (R, R)- and (S, S)-enantiomers and salmeterol in the rhesus monkey. Pulm Pharm Ther 14:289-295

4. LaForce C, Feldman G, Spangenthal S, Eckert JH, Henley M, Patalano F, D'andrea P (2016) Efficacy and safety of twice-daily glycopyrrolate in patients with stable, symptomatic COPD with moderate-to-severe airflow limitation: the GEM1 study. Int J Chronic Obstr Pulm Dis 11:1233-1243

5. Martinez FJ, Klaus FR, Ferguson GT (2017) Efficacy and safety of glycopyrrolate/formoterol metered dose inhaler formulated using co-suspension delivery technology in patients with COPD. Chest 151:340-357

6. Gousuddin M, Appala Raju S, Sultanuddin Manjunath S (2011) Development and validation of spectrophotometric methods for estimation of formoterol bulk drug and its pharmaceutical dosage forms. Int J Pharm Sci Res 3:306-310

7. Hassib ST, El-Zaher AA, Fouad MA (2011) Validated stability-indicating derivative and derivative ratio methods for the determination of some drugs used to alleviate respiratory tract disorders and their degradation products. Drug Test Anal 3:306-318

8. Sardela VF, Deventer K, Pereira HM, de Aquino Neto FR, Van Eenoo P (2012) Development and validation of a ultra high performance liquid chromatography-tandem mass spectrometric method for the direct detection of formoterol in human urine. J Pharm Biomed Anal 70:471-475
9. Kamimura H, Sasaki H, Higuchi S, Shiobara Y (1982) Quantitative determination of the beta-adrenoceptor stimulant formoterol in urine by gas chromatography mass spectrometry. J Chromatogr A 229:337-345

10. Akapo SO, Wegner M, Mamangun A, McCrea C, Asif M, Dussex JC (2004) Optimization and validation of a gas chromatographic method for analysis of (RS, SR)-diastereoisomeric impurity in formoterol fumarate. J Chromatogr A 1045:211-216

11. Campestrini J, Lecaillon JB, Godbillon J (1997) Automated and sensitive method for the determination of formoterol in human plasma by highperformance liquid chromatography and electrochemical detection. J Chromatogr B Biomed Sci Appl 704:221-229

12. Butter J, Van den Berg B, Portier E, Kaiser G, Van Boxtel C (1996) Determination by HPLC with electrochemical detection of formoterol $R R$ and SS enantiomers in urine. J Liq Chromatogr Relat Technol 19:993-1005

13. Van den Berg B, Portier E, Van den Berg M, Braat M, Van Boxtel C (1994) First high-performance liquid chromatography assay of formoterol concentrations in the low-picogram-per-milliliter range. Ther Drug Monit 16:196-199

14. Akapo S, McCrea C, Gupta J, Roach M, Skinner W (2009) Chiral HPLC analysis of formoterol stereoisomers and thermodynamic study of their interconversion in aqueous pharmaceutical formulations. J Pharm Biomed Anal 49:632-637

15. Nadarassan DK, Chrystyn H, Clark BJ, Assi KH (2007) Validation of highperformance liquid chromatography assay for quantification of formoterol in urine samples after inhalation using UV detection technique. J Chromatogr B Anal Technol Biomed Life Sci 850:31-37

16. Akapo SO, Asif M (2003) Validation of a RP-HPLC method for the assay of formoterol and its related substances in formoterol fumarate dihydrate drug substance. J Pharm Biomed Anal 33:935-945

17. Deventer K, Pozo OJ, Delbeke FT, Van Eenoo P (2012) Quantitative detection of inhaled formoterol in human urine and relevance to doping control analysis. Drug Test Anal 4:449-454

18. Mascher DG, Zech K, Nave R, Kubesc KM, Mascher HJ (2006) Ultra-sensitive determination of Formoterol in human serum by high performance liquid chromatography and electrospray tandem mass spectrometry. J Chromatogr B Biomed Sci Appl 830:25-34

19. Cherkaoui S, Faupel M, Francotte E (1995) Separation of formoterol enantiomers and detection of zeptomolar amounts by capillary electrophoresis using laser-induced fluorescence. J Chromatogr A 715:159-165

20. Song JZ, Chen J, Tian SJ, Sun ZP (1999) Assay for the determination of low dosage form of formoterol dry syrup by capillary electrophoresis with head-column field-amplified sample stacking. J Pharm Biomed Ana 21:569-576

21. He Y, Li X, Tong P, Lu M, Zhang L, Chen G (2013) An online field-amplification sample stacking method for the determination of $\beta_{2 \text {-agonists in }}$ human urine by CE-ESI/MS. Talanta 104:97-102

22. Ghany MFA, Hussein LA, Magdy N, Yamani HZ (2016) Simultaneous spectrophotometric determination of indacaterol and glycopyrronium in a newly approved pharmaceutical formulation using different signal processing techniques of ratio spectra. Spectrochim Acta A Mol Biomol Spectrosc 157:251-257

23. Ebeid MY, Moussa BA, Malak AAA (1986) Analysis of some antispasmodic drugs: oxyphencyclimine and glycopyrronium bromide. Pharm Week 8:252-258

24. Yao SZ, Liu GH (1985) Glycopyrronium-selective electrodes. Talanta 32:1113-1117

25. Murray GR, Calvey TN, Williams NE, Chan K (1984) Quantitative capillary column gas chromatographic method for the determination of glycopyrronium in human plasma. J Chromatogr B Biomed Sci Appl 308:143-151

26. Lakshmana RA, Mukkanti EM, Vijay K (2017) Stability indicating RP-HPLC method for simultaneous determination of neostigmine methylsulfate and glycopyrrolate bromide in bulk and pharmaceutical formulation. Oper Inn Biol Al Sci 1:71-78

27. Jamdar P, Meshram D (2015) Isoabsorptive point method for the simultaneous estimation of neostigmine methyl sulphate and glycopyrrolate in injectable dosage form. J Fons Sci Pharm Clin Res 4:5-8

28. Gandla K, Pabba P, Akula G (2011) RP-HPLC method development and validation for estimation of glycopyrrolate in bulk and tablet dosage forms. Asian J Pharm Clin Res 4:37-40 
29. Nebiu D, Walter M, Lachmann B, Kopelent H, Noe CR (2007) Determination of $(R, R)$ glycopyrronium bromide and its related impurities by ion pair HPLC. Pharmazie 62:406-410

30. Rumpler MJ, Sams RA, Colahan P (2011) Validation of a liquid chromatography tandem mass spectrometry method for quantification of glycopyrrolate in horse plasma. J Anal Toxicol 35:656-664

31. Storme ML, t'Kindt RS, Goeteyn W, Reyntjens K, Van Bocxlaer JF (2008) Quantitative determination of glycopyrrolate in human plasma by liquid chromatography-electrospray ionization mass spectrometry: the use of volatile ion-pairing agent during both liquid-liquid extraction and liquid chromatography. J Chromatogr B Biomed Sci Appl 876:24-30

32. Clarke EGC, Moffat AC (2011) Clarke's analysis of drugs and poisons. Pharmaceuticals, body fluids and postmortem material, 4th edn. Pharmaceutical Press, London (Electronic version)

33. Webster A, Pamme N (2010) Book review: ion-pair chromatography and related techniques. Bioanalysis 2:1179-1180

34. Cecchi T (2007) Application of ion pairing chromatography to the analysis of inorganic analytes: review. J Liq Chromatogr Relat Technol 30:1205-1225

35. Kelly M, Altria K, Clark B (1997) Quantitative analysis of sodium dodecyl sulphate by capillary electrophoresis. J Chromatogr A 781:67-71
36. The US Pharmacopoeial Convention, The US Pharmacopoeial Convention (2011) The United States pharmacopoeia XXXIV, the National Formulary XXIX, vol I \& II. The US Pharmacopoeial Convention, Rockville (electronic version)

37. ICH (2005) International conference on harmonization: harmonized tripartite guideline, validation of analytical procedures: text and methodology, Q2(R1), Current Step 4 Version, 2005. http://www.ich.org/filea dmin/Public_Web_Site/ICH_Products/Guidelines/Quality/Q2_R1/Step4/ Q2 R1 Guideline.pdf. Accessed 2018

38. Miller J, Miller JC (2018) Statistics and chemometrics for analytical chemistry. Pearson Education, London

39. Akram NM, Umamahesh M (2017) A new validated RP-HPLC method for the determination of glycopyrrolate and formoterol fumarate in its bulk and pharmaceutical dosage form. Orient J Chem 33:1492-1501

\section{Publisher's Note}

Springer Nature remains neutral with regard to jurisdictional claims in published maps and institutional affiliations.
Ready to submit your research? Choose BMC and benefit from:

- fast, convenient online submission

- thorough peer review by experienced researchers in your field

- rapid publication on acceptance

- support for research data, including large and complex data types

- gold Open Access which fosters wider collaboration and increased citations

- maximum visibility for your research: over $100 \mathrm{M}$ website views per year

At BMC, research is always in progress.

Learn more biomedcentral.com/submissions 